\title{
Assessing farmers' contribution to greenhouse gas emission and the impact of adopting climate-smart agriculture on mitigation
}

\author{
Michael Ayeah Israel, Joseph Amikuzuno and Gideon Danso-Abbeam*i)
}

\begin{abstract}
Background: The adoption of climate-smart agricultural (CSA) practices is expected to improve farmers' adaptation to climate change and also increase yields while simultaneously curbing greenhouse gas (GHG) emissions. This paper explores the determinants of smallholder farmers' participation in GHG-emitting activities. It also estimates the impact of CSA activities on reducing GHG emissions.

Methods: The findings are based on survey data obtained from 350 smallholder farmers in the East Gonja district of Northern Ghana. We adopted the generalized Poisson regression model in identifying factors influencing farmers' participation in the GHG emission practices and inverse-probability-weighted regression adjustment (IPWRA) to estimate the impact of CSA adoption on GHG emissions.

Results: Most farming households engaged in at least one emission activity. The findings of the generalized Poisson model found that wealthier households, higher education, and households with access to extension services were less likely to participate in GHG emission activities. There was also evidence that CSA adoption significantly reduces GHG emissions.
\end{abstract}

Conclusion: Advocacy in CSA adoption could be a necessary condition for environmental protection through the reduction of GHG emissions.

Keywords: Climate-smart agriculture, Emission, Mitigation, Adoption, Under-dispersion, Count models, Treatment effect

\section{Background}

Climate change and its effects pose a major global challenge to both agricultural growth and human welfare efforts, especially in sub-Saharan Africa (SSA). The steady decline in agricultural productivity followed by food price increases has severe implications for food security, particularly in developing countries where there is a high degree of vulnerability to climate change (FAO 2016). In SSA, where the majority of the population

\footnotetext{
* Correspondence: dansoabbeam@uds.edu.gh

Department of Agricultural and Resource Economics, University for Development Studies, Tamale, Ghana
}

\section{Springer Open}

(c) The Author(s). 2020 Open Access This article is licensed under a Creative Commons Attribution 4.0 International License, which permits use, sharing, adaptation, distribution and reproduction in any medium or format, as long as you give appropriate credit to the original author(s) and the source, provide a link to the Creative Commons licence, and indicate if changes were made. The images or other third party material in this article are included in the article's Creative Commons licence, unless indicated otherwise in a credit line to the material. If material is not included in the article's Creative Commons licence and your intended use is not permitted by statutory regulation or exceeds the permitted use, you will need to obtain permission directly from the copyright holder. To view a copy of this licence, visit http://creativecommons.org/licenses/by/4.0/.

relies on climate-sensitive practices, primarily in agricultural production, climate change and variability poses a developmental challenge (Thompson et al. 2010; IFPRI 2010). In Ghana, climate change is predicted to affect crop production, food security, water security, and energy supply in the country's northern regions, especially in the agricultural sector (Stanturf et al. 2011; Akudugu et al. 2012). The challenges faced in these regions are amplified by the harsh climate and distance from the nation's administrative capital (Sova et al. 2014) with majority of the farmers in these locations depending on farming as their primary occupation. According to Thamaga-Chitja and Morojele (2014), the marginal areas 
of these rural smallholder farmers, coupled with their low level of technical expertise and the various barriers to accessing essential farming agricultural resources, are particularly prone to the effects of climate change.

The agricultural sector is also expected to make a significant contribution to the proportion of GHG emissions resulting from climate change. According to Czyżewski and Kryszak (2018), agricultural practices contribute about $25-30 \%$ of GHG emissions. Agricultural activities contribute about $17 \%$ to GHG emissions and $7-14 \%$ to land use change (OECD 2015). In addition to industry and transport, it contributes significantly to GHG emissions through a number of activities, such as land clearing, biomass or wood burning, and tilling or agrochemical use, all of which increase the effects of climate change by releasing GHGs (FAOSTAT, 2015). In addition, agriculture in tropical developing countries is estimated to account for 7-9\% of anthropogenic GHG emissions annually (Smith et al. 2014).

In Ghana, total GHG emissions increased by $20 \%$ between 1990 and 2011 (WRI 2015). With the exception of emissions from industrial processes, total GHG emissions in all sectors have increased in the country, with growth in emissions dominated by agriculture, forestry, and other land use (AFOLU) sectors. According to the Ministry of Environment, Science, Technology and Innovation (MESTI), the growing trend of emissions in the AFOLU sector since 1990 has resulted from the conversion of forests to cropland and grassland, an increase in the population of animals, burning biomass through wildfires, crop production, and fertilizer use, as well as other associated emissions (MESTI 2015).

Various methods of mitigation of GHG emissions have been proposed. Robertson (2004) identified strategies that could significantly reduce net $\mathrm{CO}_{2}$ emissions from the agriculture sector. These include (1) improving farm operations that consume fuel that leads to energy efficiency gains, (2) soil carbon sequestration through changes in tillage, (3) crop residues and animal waste management and use of cover crops, (4) production and use of biofuels and bio-based materials technology to offset the use of fossil fuels for energy production, and (5) agricultural production and yields efficiency for livestock and crops to offset the need to expand lands for agricultural production resulting in carbon losses. Smith et al. (2008) categorize GHG mitigation potentials into three categories, namely emission reduction, elimination, and emission prevention. In reducing emissions, the instability of GHGs is potentially reduced by the efficient management of carbon and nitrogen flows in the agro-ecosystem (Smith et al. 2008). Unfortunately, many developing countries view the move to focus on agricultural emissions as a threat to stifle their growth and reduce the burden of mitigation on developing countries (Chandra et al. 2016).

Climate-smart agriculture (CSA) integrates the three dimensions of sustainable development (economic, social, and environmental) by jointly addressing food security and climate challenges through the development of technical, policy, and investment conditions to achieve sustainable food security in agricultural development (FAO, 2013). The CSA term was developed to represent strategies to address climate change challenges by increasing resilience to extreme weather conditions, climate change adaptation, and the reduction of greenhouse gases from agricultural sources that contribute to global warming (Steenwerth et al. 2014). CSA practices are not or must not necessarily be new; in fact, according to Schaller et al. (2017), any agricultural practice or technique that contributes to the achievement of the three pillars can be considered climate-smart. The different techniques employed in CSA often perform differently over the components and, as a result, have to be combined as an integrated approach to complement each other to maximize the benefits (FAO 2015).

Despite the high vulnerability to climate change in the Savannah region of Ghana, burning has been identified as a major contributor to anthropogenic sources of agricultural GHG emissions (FAO 2016). It is therefore imperative to address both issues simultaneously in order to ensure the sustainability of agricultural production in the region. Climate change studies, particularly in the SSA, have focused on adaptation strategies, their effect on farmers and households, as well as on farmers' perception of climate change. Although the agricultural sector has been shown to make a significant contribution to global GHG emissions, little attention has been paid to the contribution of farmers to emissions or mitigation as they adapt to climate change. This study seeks to assess the level of participation in emissions practices, to identify factors that influence the participation of smallholders in emissions practices, and to estimate the impact of climate change adaptation strategies on the reduction of GHG emissions.

\section{Methods}

\section{Study area and data collection}

For this study, data was acquired from a 2018 survey of 350 households in the East Gonja district of the Savannah Region of Ghana. A multistage sampling procedure was employed for this study. In the first stage, the district was stratified into a beneficiary and nonbeneficiary communities. A beneficiary community is a community where the CSA technologies have been disseminated and these communities were identified from a list obtained from extension agencies promoting CSA practices in the district. A non-beneficiary community is 
one where the technologies were not directly introduced. In the second stage, simple random sampling was used to select 15 communities, 10 and 5 communities from the pool of beneficiary and non-beneficiary communities, respectively. In the final stage, households from each of the selected communities were selected randomly for the study. The households are mostly smallholder producers, with farm holdings less than 2 hectares (MOFA 2006), cultivating crops like maize, rice, yam, groundnut, cowpea, and soybean primarily under rain-fed conditions.

\section{Conceptual and analytical techniques}

The primary objective of this study is to empirically identify factors that influence the intensity of participation in emission practices and whether adoption of climate-smart agricultural practices reduces participation in emission practices. Thus, we hypothesized that adoption of climate-smart agricultural practices discourages farmers and their households from engaging in practices that would lead to GHG emissions. The study, therefore, uses two analytical techniques to achieve its objectives. First, count data modelling was used to identify the determinants of the intensity of participation in GHG emissions. Second, the study employed inverseprobability-weighted regression adjustment (IPWRA) estimator within the framework of the propensity score to estimate the causal effect of CSA adoption on participation in GHG emission practices.

\section{Count data model-generalized Poisson model}

The number of practices farm households engage that give rise to emissions defines the dependent variable conceptualized as the intensity of participation in emission practices. The GHG practices under consideration in this study are bush burning as part of hunting, bush burning as part of land preparation, burning crop residues after cultivation, and tree cutting for fuelwood. Following Cameron and Trivedi (1990) and Greene (2008), the number of emission practices by farmers could be modelled under the framework of count data modelling. This is because the dependent variable (intensity of participation in emission) is a numerical count by its nature. The count data model has been used in numerous studies where the dependent variable is count (e.g. Nkegbe and Shankar 2014; Sharma et al. 2011; Isgin et al. 2008; Rahelizatovo and Gillespie 2004; Lohr and Park 2002). Given that there is a random occurrence of the number of practices farmers engaged in to give rise to emission, the appropriate probability distribution is the Poisson distribution. The intensity of participation in emission practices can be modelled using the standard Poisson because, at any given $y_{i}$, an integer of counts can be said to come from a Poisson distribution as shown in Greene (2008).
We also run an alternative count model to cater for limitations should the equidispersion assumption not hold. The generalized Poisson regression (GPR) is a flexible count data approach capable of handling count data of any nature, under, over, or equidispersion. The GPR has been studied by Famoye (1993) and has been used in modelling the number of accidents and some covariates by Famoye et al. (2004). The GPR has also been recently used by Mahama et al. (2020) to model underdispersed count-dependent variable. The mathematical formulation for count data models, and GPR in particular can be found in studies such as Famoye (1993), Famoye et al. (2004), and Mahama et al. (2020). These mathematical formulation and models were not presented in this study for brevity, and lack of space ${ }^{1}$.

\section{Inverse-probability-weighted regression adjustment (IPWRA)}

The study also adopts the inverse-probability-weighted regression adjustment (IPWRA) estimator in estimating the treatment effect of CSA adoption on the participation in emission practices. IPWRA estimator possesses a double-robust property, and it also serves as a reliable solution for possible biassed estimates (Bourguignon et al. 2007; Robins et al. 2007). It was also noted by Wooldridge (2007) that even under situations of treatment or outcome misspecifications, IPWRA estimates would still be consistent but not when both are misspecified. The primary aim of using the IPWRA estimator is to measure the impact of adopting CSA in reducing the participation of emission practices, measured by the average treatment effect on the treated (ATT), which is the average effect of the treatment limited to the individuals receiving the treatment (CSA adopters). Other parameters, such as the average treatment effect (ATE) and the potential outcome means (POM) were also estimated. ATE is the average effect of the treatment among all individuals in the sample/population under consideration. On the other hand, the POMs are the potential outcomes given a specific treatment level (adoption or non-adoption). Again, the mathematical formulations and the model specifications for the IPWRA can be found in Imbens and Wooldridge (2009) ${ }^{2}$.

\section{Results and discussion \\ Variable definition The dependent variables}

The number of emission practices engaged by households is the dependent variable for this study. However, these practices are limited to agriculture, land use,

\footnotetext{
${ }^{1}$ Readers are kindly requested to consult those references for further knowledge.

${ }^{2}$ Readers are kindly requested to consult Imbens and Wooldridge (2009).
} 
forestry, tree cutting, and burning activities, in recognition of the fact that burning in the Savannah is the main source of emissions in the agricultural sector in Ghana (FAOSTAT 2015). Emissions practices include cutting trees for fuelwood, burning bush while hunting for small game, burning bush as part of land clearing activities, and burning bush after cultivation. The number of emission practices in which households participated is shown in Table 1.

Table 1 shows that the majority of the sampled households participated in at least one of the GHG emission practices. Six (6\%) of the sampled households did not participate in any of the GHG emission practices, while $41.14 \%$ of the households were into all four emission contributing practices. In addition, about $8.29 \%$ participated in only one of the practices contributing to GHG emissions from the agricultural sector in Ghana. The remaining $22 \%$ and $22.57 \%$ of the sampled households were into two and three of the practices contributing to GHG emissions in the study area, respectively. Table 2 shows the types of emission practices engaged by households. Bush burning as part of land preparation and tree cutting were the most common emission practices among households in the study area, accounting for approximately $86 \%$ and $87 \%$, respectively. Burning crop residues after cultivation and bush burning during hunting had relatively low participation compared to the former but still had more than $50 \%$ of the sample participating.

The CSA practices have been classified into three main categories: soil conservation practices, livelihood diversification and irrigation, and water harvesting.

Soil conservation practices aimed at improving soil fertility and structure and they include creating swales, composting, or application of decayed organic domestic waste, and crop residues improve soil fertility, making, controlling bush, and ploughing crop residues back into the soil. Livelihood diversification strategies are aimed mostly at minimizing weather-induced losses and also stabilize incomes of farmers as well as their households. The approaches considered in this study include rearing livestock for commercial purposes, beekeeping, and soya cultivation as an alternative to the cultivation of traditional crops and its processing and dry season vegetable

Table 1 Distribution of counts of emission practices

\begin{tabular}{lll}
\hline Emission practice (counts) & Frequency & Percent \\
\hline 0 & 21 & 6 \\
1 & 29 & 8.3 \\
2 & 77 & 22.0 \\
3 & 79 & 22.6 \\
4 & 144 & 41.1 \\
Total & 350 & 100.0 \\
\hline
\end{tabular}

Table 2 Distribution of households' participation in emission practices

\begin{tabular}{lll}
\hline Emission practice & Frequency & Percent \\
\hline Bush burning before cultivation & 300 & 85.7 \\
Tree cutting & 304 & 86.9 \\
Burning crop residues after cultivation & 199 & 56.7 \\
Bush burning during hunting & 193 & 55.1 \\
\hline
\end{tabular}

farming. Irrigation and water harvesting practices include the use of manual pumps to support the continuous cultivation of crops during the dry seasons when droughts become severe. Water harvesting helps households harness water, which can be used in irrigation and also domestic activities for the same reason. Table 3 is a summary of the CSA practices adopted by respondents in the study area.

\section{The independent variables}

The probability of participation in emission practices is hypothesized to be influenced by variables which are categorized as household and personal characteristics, institutional characteristics, and climate change perceptions.

Table 4 reports the descriptive statistics of the vector of explanatory variables included in the model. Household size, education status of household head, farm size, wealth (welfare per capita), production intention, and farming experience were some of the household and personal characteristics considered. According to Adeoti (2008), larger households are expected to adopt improved technology and could also mean labour

Table 3 Summary of CSA practice adoption

\begin{tabular}{lll}
\hline CSA practice & Adopters (\%) & Non-adopters (\%) \\
\hline Soil conservation practices & $\mathbf{6 7 . 7}$ & $\mathbf{3 2 . 2 9}$ \\
Creation of swales & 10.86 & 89.14 \\
Compost application & 11.43 & 88.57 \\
Making contours & 25.43 & 74.57 \\
Bush burning control & 55.14 & 44.86 \\
Ploughing crop residues into soil & 38.86 & 61.14 \\
Livelihood diversification & $\mathbf{6 6 . 0 0}$ & $\mathbf{3 4 . 0 0}$ \\
Commercial livestock production & 58.86 & 41.14 \\
Soya cultivation & 13.71 & 86.29 \\
Soya processing & 9.71 & 90.29 \\
Dry season gardening & 7.43 & 92.57 \\
Beekeeping & 2.29 & 97.71 \\
Irrigation and water harvesting & $\mathbf{4 1 . 7 1}$ & $\mathbf{5 8 . 2 9}$ \\
Water harvesting & 39.14 & 60.86 \\
Manual pump irrigation & 2.86 & 97.14 \\
Total = 350 & & \\
\hline
\end{tabular}


Table 4 Variable definition and descriptive statistics

\begin{tabular}{|c|c|c|c|}
\hline Variable & Definition & Mean & Standard deviations \\
\hline \multicolumn{4}{|l|}{ Dependent variable } \\
\hline Emission & Number of participated emission practices (counts) & 2.846 & 1.22 \\
\hline \multicolumn{4}{|l|}{ Explanatory variables } \\
\hline Household size & Number of household members & 8.46 & 4.42 \\
\hline Education & Highest level of education of household head (years) & 3.85 & 5.10 \\
\hline Off-farm revenue & Alternative income source aside farming ( 1 if yes, 0 if no) & 0.26 & 0.44 \\
\hline Farm size & Total size of land cultivated (acres) & 8.14 & 6.55 \\
\hline Experience & Number of years of farming & 20.22 & 13.31 \\
\hline FBO membership & Membership of farmer-based organization ( 1 if yes, 0 if no) & 0.26 & 0.44 \\
\hline Extension access & Contact with extension agent ( 1 if yes, 0 if no) & 0.64 & 0.48 \\
\hline Credit access & Access to credit for farming activities ( 1 if yes, 0 if no) & 0.33 & 0.47 \\
\hline Production intention & Primary purpose for farming ( 1 if commercial, 0 if subsistence) & 0.40 & 0.49 \\
\hline Climate change awareness & Whether a farmer has knowledge of climate change ( 1 if yes, 0 if no) & 0.72 & 0.45 \\
\hline CSA training & Farmer participation in CSA training ( 1 if yes, 0 if no) & 0.15 & 0.36 \\
\hline CSA adopter & Farmer adoption of CSA practices ( 1 if yes, 0 if no) & 0.87 & 0.33 \\
\hline Welfare & Household monthly per capita expenditure & 277.40 & 304.82 \\
\hline \multicolumn{4}{|l|}{ Perception of causes } \\
\hline Naturally & Average index of perception climate change occurring as a result of natural events & 1.04 & 1.14 \\
\hline Deforestation & Average index of perception climate change occurring as a result of deforestation & 0.75 & 1.32 \\
\hline Bush burning & Average index of perception climate change occurring as a result of bush burning & 0.33 & 1.38 \\
\hline
\end{tabular}

Mean responses for dichotomous variables (yes/no) represent the percentage of yes responses

availability for land clearing activities. Conversely, resource allocation constraints in larger households could become a barrier in the adoption of improved and sustainable agricultural technologies. As a result, household size could be either positive or negative when it comes to participation in emission practices. Farmers who have attained a level of education are expected to be exposed to knowledge on the causes and effects of climate change so would take steps not to contribute to emissions. Hence, education is expected to have a negative effect on participation in emission practices in the study area. For this study, farm size refers to the total acreage cultivated by respondents. When it comes to participation in burning, larger farm sizes might be compelled to burn during land clearing. Larger farm sizes can be a symbol of wealth, and as such, burning might not be the case given that wealthier farmers may be able to hire more labour. The effect of farm size on participation in emission practices, as a result, could be either negative or positive. Given that the study area has high poverty levels, relatively wealthier households are believed to have a higher probability of adopting improved technologies and less likely to participate in emission practices. The intention of production is also expected to influence households' participation in emission practices. Households cultivating primarily for commercialization are expected to adopt practices which would result in higher yields to realize more profit at the same time. In efforts to reduce the cost of production, commercially oriented producers may result in labour and cost-saving practices which could lead to the contribution of GHG emissions.

The institutional variables hypothesized to affect the household participation in emission practices are FBO membership, extension access, credit access, and CSA training. Respondents' membership of farmer groups focused on any aspect of the agricultural production and is believed to affect participation in GHG emission practices. We expect farmers who are members of such organization to be more likely to adopt sustainable agricultural practices or CSA practices and as a result, participate less GHG emission practices. This is because there is an increased likelihood of farmer to farmer information dissemination on improved technologies and access to labour sharing if farmers belong to an FBO. Correspondingly, farmers in FBOs are more likely to get access to credit to supplement their production and offset the associated cost in technology adoption. Again, the study expects that farmers who had access to extension services, whether from the Ministry of Agriculture or any other source will be more likely to adopt improved technologies. In the context of CSA, farmers who 
get access to extension services are more likely to learn about climate change, its impact and causes. As a result, extension access should have a negative influence on participation intensity in GHG emission practices. Farmers in some communities in the study area and communities considered in this study were exposed to CSA training. Farmers who participated in the CSA training were directly introduced to CSA technologies to have knowledge about climate change, causes and impacts. This variable was measured as a dummy and is expected to increase the probability of adopting CSA technologies. The adoption of CSA practices is expected to lead to a reduction in GHGs. As such, for this study, farmers or households that adopted CSA practices are expected to participate less in the GHG emission practices in the study area. The sign in the model is expected to be negative.

Finally, climate change awareness and perception variables were also hypothesized to influence household participation in emission practices. Niles and Mueller (2016) adduce that the perceptions of individuals on climate change are connected to their support of climate policies and their alteration of their climate-related behaviours. The perception of respondents on the causes of climate change concerning anthropogenic and nonanthropogenic causes is measured on a Likert scale from -2 to 2 corresponding, respectively, from strongly disagree to strongly agree. A positive coefficient relates to individuals who agree that climate change is caused by either deforestation, or bush burning or naturally. These variables are expected to be significant in the model with the perception of anthropogenic causes having a negative sign while the others have a positive.

\section{Determinants of the intensity of GHG emission practices}

Although the basic Poisson model is theoretically attractive, it has a major shortcoming of equidispersion assumption. The assumption of equidispersion is that the variance of the count-dependent variable and its conditional mean are equal. However, some empirical studies on count data have been shown to exhibit overdispersion with the variance being greater than the mean as a result of zero observations in the dependent variable (Nkegbe and Shankar 2014). The preliminary analysis on the count-dependent variable of this study showed that the variance is less than the mean resulting in underdispersion, which can be attributed to the fact that only $6 \%$ of the information on the dependent variable was zero. The estimated dispersion parameter from the GPR model is negative $(-0.64)$, indicating under-dispersion. The likelihood ratio test gave a chi-square value of 115.13 , which is significant at $1 \%$, suggesting that the generalized Poisson model rather than the standard Poisson model is the appropriate model for the estimation. Also, we found that chi-square, AIC, and BIC for GPR are less than standard Poisson, confirming that GPR better describe the data than the standard Poisson model.

The estimates from the GPR model identifying the determinants of the intensity of GHG emission practices are reported in Table 5. The results show that education, experience, access to extension services, CSA training, CSA adoption, and welfare as well as the perception of deforestation are all negative and significant determinants of GHG emission practices. However, non-farm activities, climate change awareness, and perception on bush burning as a cause of climate change are positive and significant determinants in the GPR model.

Education was found to have a negative and significant influence on participation in emission practices. The marginal effect indicates that as respondent attain an extra year of education, the number of emission practices participated is expected to reduce by about 0.02 . This result is in line with the study's a priori expectations, given that education has a positive influence on the adoption of modern and sustainable agricultural practices. Education enables households to understand the threats and risks posed by emission practices and their overall impacts on the climate and environment. This finding confirms that of Manda et al. (2016), who also found a significant positive relationship between education and the adoption of sustainable agricultural practices in rural Zambia.

Extension access was also found to have a negative effect on the decision to intensively participate in emission practices among farmers in the study area. The variable was found to be statistically significant at $1 \%$ and shows that households who had access to extension services reduce the number of emission practices by 0.4 compared to households that did not have access to the service. These findings are also in line with our expectations and consistent with findings of the literature. For example, Kim et al. (2005) reported that the extension services had a positive effect on the adoption of best management practices among beef cattle producers in Louisiana. Similarly, Nkegbe and Shankar (2014) also established a positive relationship between extension contact and adoption of soil and water conservation practices in northern Ghana.

Farmers who participated in CSA training were also found to be less likely to participate in emission practices than those who did not. The coefficient was found to be significant at $5 \%$, indicating that respondents who received CSA training tend to reduce the number of emission practices they participated by 0.3 compared to respondents who did not. Respondents who participated 
Table 5 Count data model results

\begin{tabular}{|c|c|c|c|c|}
\hline \multirow[t]{2}{*}{ Variable } & \multicolumn{2}{|c|}{ Generalized Poisson model } & \multicolumn{2}{|l|}{ Poisson model } \\
\hline & Coefficient & Marginal effect & Coefficient & Marginal effect \\
\hline Intercept & $1.293^{* * *}(0.073)$ & - & $1.325^{* * *}(0.129)$ & - \\
\hline Household size & $-0.007(0.005)$ & $-0.020(0.014)$ & $-0.009(0.009)$ & $-0.025(0.025)$ \\
\hline Education (years) & $-0.009^{* *}(0.004)$ & $-0.025^{* *}(0.011)$ & $-0.013^{*}(0.007)$ & $-0.036^{*}(0.019)$ \\
\hline Off-farm activities revenue & $0.075^{*}(0.043)$ & $0.214^{*}(0.122)$ & $0.110(0.072)$ & $0.313(0.206)$ \\
\hline Farm size & $0.005^{*}(0.003)$ & $0.016^{*}(0.009)$ & $0.006(0.005)$ & $0.017(0.014)$ \\
\hline Experience & $-0.0009(0.002)$ & $-0.002(0.004)$ & $-0.0001(0.003)$ & $-0.002(0.008)$ \\
\hline FBO membership & $0.040(0.053)$ & $0.114(0.150)$ & $0.040(0.095)$ & $0.105(0.270)$ \\
\hline Extension access & $-0.154^{* * *}(0.043)$ & $-0.438^{* * *}(0.121)$ & $-0.164^{* *}(0.072)$ & $-0.468^{* *}(0.207)$ \\
\hline Credit access & $0.015(0.046)$ & $0.042(0.131)$ & $0.021(0.079)$ & $0.059(0.225)$ \\
\hline Production intention & $0.072^{*}(0.043)$ & $0.201^{*}(0.128)$ & $0.093(0.074)$ & $0.266(0.212)$ \\
\hline Climate change awareness & $0.142^{* * *}(0.045)$ & $0.405^{* * *}(0.128)$ & $0.198^{* *}(0.079)$ & $0.565^{* *}(0.224)$ \\
\hline CSA training & $-0.121^{* *}(0.065)$ & $-0.346^{* *}(0.184)$ & $-0.177(0.116)$ & $-0.503(0.332)$ \\
\hline CSA adopter & $-0.092^{* *}(0.042)$ & $-0.263^{* *}(0.121)$ & $-0.118(0.072)$ & $-0.336(0.205)$ \\
\hline Wealth & $-0.079^{* * *}(0.023)$ & $-0.226^{* * *}(0.066)$ & $-0.095^{* *}(0.044)$ & $-0.270^{* *}(0.125)$ \\
\hline \multicolumn{5}{|c|}{ Perception on causes of climate change } \\
\hline Natural & $-0.005(0.019)$ & $-0.014(0.054)$ & $-0.008(0.033)$ & $-0.022(0.094)$ \\
\hline Deforestation & $-0.083^{* * *}(0.022)$ & $-0.237^{* * *}(0.062)$ & $-0.112^{* * *}(0.037)$ & $-0.317^{* * *}(0.107)$ \\
\hline Bush burning & $0.049^{* *}(0.019)$ & $0.106^{* *}(0.055)$ & $0.074^{* *}(0.035)$ & $0.210^{* *}(0.099)$ \\
\hline Dispersion & \multicolumn{4}{|l|}{-0.64} \\
\hline Log likelihood & \multicolumn{2}{|l|}{-525.967} & \multicolumn{2}{|l|}{-583.534} \\
\hline Chi-squared & \multicolumn{2}{|l|}{$104.20^{* * *}$} & \multicolumn{2}{|l|}{$124.60^{* * *}$} \\
\hline AIC & \multicolumn{2}{|l|}{1083.158} & \multicolumn{2}{|l|}{1201.048} \\
\hline $\mathrm{BIC}$ & \multicolumn{2}{|l|}{1156.459} & \multicolumn{2}{|l|}{1270.491} \\
\hline Likelihood ratio test & \multicolumn{4}{|c|}{$\operatorname{LR} \operatorname{chi}^{2}(1)=115.13^{* * *}$} \\
\hline
\end{tabular}

Significant at $* 10 \%$, $*$ $5 \%$, and $* * * 1 \%$

in CSA training were more likely to implement effectively the CSA practices that led to the mitigation of GHGs. The CSA adoption variable was also found to be negative and significant at $5 \%$. The marginal effect also indicates that the adoption of CSA practices has reduced the number of emission practices that respondents participated in by 0.4 . Considering that one of the objectives of CSA is to reduce GHG emissions, this result is consistent with expectations and confirms that the adoption and practice of CSA as a way to address climate change issues positively by reducing emissions.

The household wealth, proxied by per capita household consumption expenditure, was also found to be statistically significant at $1 \%$ with a negative coefficient. As the wealth of the household increased by GHS 1.00 per household member, the number of emission practices participated decreased by 0.23 . Wealth is believed to contribute to the adoption of improved farming practices. Regarding the emission practices, the relationship between wealth and participation in the practices has also proved to be favourable. This finding is consistent with the expectation of the study, given that wealthier households can afford to bear the cost of adopting sustainable agricultural practices.

Households whose main purpose of production is family consumption tend to contribute less to emission practices than those produced for commercial purposes. The marginal effect value of 0.2 indicates that households cultivating for commercial purposes are more likely to participate in emission practices by 0.2 more than households cultivating for subsistence reasons. This result could be attributed to the fact that households producing for family consumption tend to cultivate on small farmlands, making land clearing easier and burning unnecessary. Non-farm income was also found to have a positive and significant coefficient, implying that households with alternative income streams tend to be more involved in emission-related practices in the study area, ceteris paribus. The associated marginal effect shows that individuals who have an alternative 
source of income other than farming have participated 0.2 times more in emission practices than those who have not. This finding was contrary to our expectations. Farm size also had a positive and significant coefficient with a corresponding marginal effect of 0.016 , indicating that the participation in emission practices increased by 0.016 as the farm size increased by an acre. This finding is consistent with the a priori expectation, given that larger farm sizes may require more labour to clear before and after production. Most farmers would rather resort to burning the crop residues after production or during clearing without any form of control because of the farm sizes. It is relatively easier to clear smaller farms using limited labour and even employ fire management practices where burning is practised.

In terms of farmers' perceptions on the causes of climate change and how they influence their participation in emission practices, it was revealed that their perceptions on anthropogenic causes, deforestation and bush burning, have a significant effect on GHG emissions. The perception of deforestation as the cause of climate change had a negative coefficient with an associated marginal effect of -0.2 and that of bush burning with a positive coefficient and corresponding marginal effect of 0.106. The results indicate that respondents who were generally opposed to climate change as a result of deforestation were likely to contribute more to GHG emissions than those who agreed. The result is in line with the a priori expectation. It indicates that farmers are sensitive to environmental issues and are likely to desist from certain activities which could have a negative impact on the environment.

The result for the bush burning also indicates that respondents who generally agreed that bush burning was one of the contributing factors of climate change were more likely to participate in emission practices, holding all other variables constant. This result was contrary to our expectation and the ascertions made by Niles and Mueller (2016). Practices such as burning during hunting are practices that have been practiced in the study area since childhood. These acts form a fundamental part of their culture and, as such, become a challenge for individual to abandon them, since they would essentially mean abandoning part of their culture.

Again, burning during land clearing provides a cheaper alternative for some farmers as opposed to other approaches. Resource-constrained smallholders are likely to opt for burning over other land clearing options to save cost irrespective of the cost to the environment.

\section{Average adoption effect of CSA on emission practices: IPWRA estimator}

The estimated effects of climate-smart agricultural technology adoption on emissions from the IPWRA estimator is presented in Table 6 . In estimating this effect, the outcome indicators of the adopters group are compared with the outcome indicators of the same group had they not adopted (the counterfactual situation). This is known as the average treatment effect on the treated. The results indicate that the adoption of CSA practices has led to a reduction in the likelihood of participating in emission practices by 0.596 in the population. Thus, estimated ATE suggests that an average household in the population will have 0.596 less probability to engage in practices that will lead to GHG emissions if CSA is adopted. Similarly, the conditional treatment effect which measures ATT of CSA adoption on GHG emissions is 0.623 . Thus, the average farm household in the CSA adoption group would be 0.623 less likely to engage in practices that would lead to GHG emissions.

The POM shows that if none of the household in the sample adopts any of the CSA practices, they will participate in about three practices leading to GHG emission. The results, therefore, confirmed the effectiveness of CSA practices in the mitigation of GHG emissions in the study area.

\section{Conclusions}

Empirical results of the study highlighted that education, access to extension, and household wealth play vital roles in reducing GHG emissions. Improving access to the extension services and education will increase mitigation efforts, particularly in rural farming communities. In addition, by improving access to credit for farmers, they are more likely to adopt CSA technologies that, in turn, are likely to contribute to GHG mitigation. The study also showed that having the right understanding of the causes of climate change does not automatically correlate with altering their climate-related behaviours as some studies have indicated. The intensity of participation in emission practices was high among respondents who generally perceived bush burning as one of the causes of climate change, alluding to the fact that some of the practices of burning are tied to people's culture. It would therefore require the collaborative effort of the traditional authorities to deter individuals from such practices.

On the effectiveness of adoption of CSA technology in reducing GHG emissions in the study area, the

Table 6 IPWRA estimates of ATE and ATT

\begin{tabular}{lll}
\hline Treatment effects & Coefficient & Standard error \\
\hline Average treatment effect (ATE) & $-0.596^{* * *}$ & 0.155 \\
Treatment effect on the treated (ATT) & $-0.623^{* * *}$ & 0.155 \\
Potential outcome mean (POM) & $3.402^{* * *}$ & 0.141
\end{tabular}

Significant at ${ }^{*} 10 \%$, ${ }^{*} 5 \%$, and ${ }^{* *} 1 \%$ 
empirical results showed that households that adopted CSA technologies were less likely to contribute to GHG emissions by reducing their participation in emission practices. As such, it can be concluded that the adoption of CSA can be used as a tool for reducing GHG emissions from agricultural sources. The implementation of CSA technologies should be considered by the government as part of its policy for meeting the intended national determined contribution and other climate change mitigation plans of the country. The methodological approach is considered robust, given that the study yields near-uniform estimates across both Poisson and generalized Poisson models as well as the IPWRA.

\section{Acknowledgements}

The authors are grateful to the enumerators and the farmers who sat for a long time during the survey to answer the questionnaire.

\section{Authors' contributions}

All authors contributed to the different stages of this study. MAI conceptualized the idea, collected the data, was involved in the analysis of the data, and wrote the draft manuscript. JA supervised the study and provided comments on the manuscript. GDA was actively involved in the data analysis and interpretation and supervised the progress of the work. All authors read and approved the final manuscript.

\section{Funding}

No funding was received for this research.

\section{Availability of data and materials}

The datasets used to analyse this study are available from the corresponding author on reasonable request.

\section{Ethics approval and consent to participate}

During the survey, verbal consent was obtained from each respondent, and confidentiality was maintained by assigning codes for each respondent instead of recording their names. Participants of the study were informed that they have the full right to discontinue or refuse to participate in the study. As a result, all participants in the research, including survey households, enumerators, supervisors, and key informants, were fully informed of the objectives of the study. They were approached in free moods until the end of the survey.

\section{Consent for publication}

Not applicable

\section{Competing interests}

The authors declare that there exists no competing interest.

Received: 15 April 2020 Accepted: 7 August 2020

Published online: 28 September 2020

\section{References}

Adeoti Al (2008) Factors influencing irrigation technology adoption and its impact on household poverty in Ghana. J Agric Rural Dev Tropics Subtropics 109(1):51-63

Akudugu MA, Dittoh S, Mahama ES (2012) The implications of climate change on food security and rural livelihoods: experiences from Northern Ghana. J Environ Earth Sci 2(3):21-29

Bourguignon F, Fournier M, Gurgand M (2007) Selection bias corrections based on the multinomial logit model: Monte Carlo comparisons. J Econ Surv 21(1): 174-205

Cameron AC, Trivedi PK (1990) Regression-based tests for overdispersion in the Poisson model. J Econ 46(3):347-364
Chandra A, McNamara KE, Dargusch P, Damen B, Rioux J, Dallinger J, Bacudo I (2016) Resolving the UNFCCC divide on climate-smart agriculture. Carbon Manag 7(5-6):295-299

Czyżewski B, Kryszak $Ł$ (2018) Impact of different models of agriculture on greenhouse gases (GHG) emissions: a sectoral approach. Outlook Agric 47(1): 68-76

Famoye F (1993) Restricted generalized Poisson regression model. Comm Stat Theory Methods 22(5):1335-1354

Famoye F, Wulu JT, Singh KP (2004) On the generalized Poisson regression model with an application to accident data. J Data Sci 2:287-295

FAO (2013) Climate-Smart Agriculture Sourcebook. Food and Agriculture Organization of the United Nations, Rome. http://www.fao.org/docrep/018/ i3325e/i3325e04.pdf.

FAO (2016) The state of food and agriculture: climate change, agriculture and food security. Rome

FAOSTAT (2015) Agriculture organization of the United Nations, 2011. FAO, retrieved am from http://faostat3.fao.org/faostat-gateway/go/to/download/ Q/QC/S.Acceso,20.

Greene WH (2008) The econometric approach to efficiency analysis, In: Fried HO, Lovell CAK, Schmidt SS (eds) The measurement of productive efficiency and productivity growth. Oxford University Press, New York. pp 92-250

IFPRI (2010) Strategies for adapting to climate change in rural Sub-Saharan Africa. IFPRI Discussion Paper 01013.

Imbens GW, Wooldridge JM (2009) Recent developments in the econometrics of program evaluation. J Econ Lit 47(1):5-86

Isgin T, Bilgic A, Forster DL, Batte MT (2008) Using count data models to determine the factors affecting farmers' quantity decisions of precision farming technology adoption. Comput Electron Agric 62(2):231-242

Kim S, Gillespie JM, Paudel KP (2005) Count data analysis of the adoption of best management practices in beef cattle production (No. 1365-2016-108155).

Lohr L, Park TA (2002) Choice of insect management portfolios by organic farmers: lessons and comparative analysis. Ecol Econ 43(1):87-99

Mahama A, Awuni JA, Mabe FN, Azumah SB (2020) Modelling adoption intensity of improved soybean production technologies in Ghana - a Generalized Poisson approach. Heliyon 6:e03543.

Manda J, Alene AD, Gardebroek C, Kassie M, Tembo G (2016) Adoption and impacts of sustainable agricultural practices on maize yields and incomes: evidence from rural Zambia. J Agri Econ 67(1):130-153.

MESTI (2015) Ghana's first biennial update report. Ministry of Environments, Science, Technology, and Innovation (MESTI), Accra, Ghana

Ministry of Food and Agriculture (MOFA) (2006) Agriculture in Ghana: facts and figures. Annual report compiled by the Statistics, Research and Information Directorate (SRID), Ministry of Food and Agriculture (MOFA) as part of MOFA's Policy Planning Monitoring and Evaluation activities, Accra

Niles MT, Mueller ND (2016) Farmer perceptions of climate change: associations with observed temperature and precipitation trends, irrigation, and climate beliefs. Glob Environ Chang 39:133-142

Nkegbe PK, Shankar B (2014) Adoption intensity of soil and water conservation practices by smallholders: evidence from Northern Ghana. Bio-based Appl Econ 3:159-174

OECD (2015) Agriculture and climate change. Trade Agric Direc (September):6

Rahelizatovo NC, Gillespie JM (2004) The adoption of best-management practices by Louisiana dairy producers. J Agric Appl Econ 36(1):229-240

Robertson GP (2004) Abatement of nitrous oxide, methane, and the other non$\mathrm{CO}_{2}$ greenhouse gases: the need for a systems approach. In: Field CB, Raupach MR (eds) The Global Carbon Cycle. Island Press, Washington, DC, pp 493-506

Robins J, Sued M, Lei-Gomez Q, Rotnitzky A (2007) Comment: Performance of double-robust estimators when "inverse probability" weights are highly variable. Stat Sci 22(4):544-559

Schaller M, Barth El, Blies D, Röhrig F, Schümmelfeder M (2017) Climate smart agriculture (CSA): conservation agriculture (CA)

Sharma N, Singh NK, Bhadwal MS (2011) Relationship of somatic cell count and mastitis: an overview. Asian Australas J Anim Sci 24(3):429-438

Smith P, Bustamante M, Ahammad H, Clark H, Dong H, Elsiddig EA et al (2014) Agriculture, forestry and other land use (AFOLU). In: Climate change 2014: mitigation of climate change. Contribution of Working Group III to the Fifth Assessment Report of the Intergovernmental Panel on Climate Change. Cambridge University Press, pp 811-922

Smith P, Martino D, Cai Z, Gwary D, Janzen H, Kumar P et al (2008) Greenhouse gas mitigation in agriculture. Philos Trans R Soc B Biol Sci 363(1492):789-813 
Sova C, Chaudhury AS, Nelson W, Nutsukpo DK, Zougmoré RB (2014) Climate change adaptation policy in Ghana: priorities for the agriculture sector.

Stanturf JA, Warren ML, Charnley S, Polasky SC, Goodrick SL, Armah F, Nyako YA (2011) Ghana climate change vulnerability and adaptation assessment. United States Agency for International Development, Washington DC Steenwerth KL, Hodson AK, Bloom AJ, Carter MR, Cattaneo A, Chartres CJ et al. (2014) Climate-smart agriculture global research agenda: scientific basis for action. Agric Food Sec 3(1):11

Thamaga-Chitja JM, Morojele P (2014) The context of smallholder farming in South Africa: towards a livelihood asset building framework. J Hum Ecol 45(2):147-155

Thompson HE, Berrang-Ford L, Ford JD (2010) Climate change and food security in Sub-Saharan Africa: a systematic literature review. Sustainability 2(8):27192733

Wooldridge JM (2007) Inverse probability weighted estimation for general missing data problems. J Econ 141(2):1281-1301

WRI (2015) Climate analysis indicators tool: WRI's climate data explorer. World Resources Institute, Washington, DC. http://cait2.wri.org

\section{Publisher's Note}

Springer Nature remains neutral with regard to jurisdictional claims in published maps and institutional affiliations.

\section{Submit your manuscript to a SpringerOpen ${ }^{\circ}$ journal and benefit from:}

- Convenient online submission

- Rigorous peer review

- Open access: articles freely available online

- High visibility within the field

- Retaining the copyright to your article

Submit your next manuscript at $\boldsymbol{\triangleright}$ springeropen.com 